\title{
Lichen sclerosus associated with localized scleroderma: dermoscopy contribution*
}

\author{
Monisa Martins Nóbrega ${ }^{1}$ \\ Mariana César Corrêa ${ }^{1}$ \\ Aline Lopes Bressan ${ }^{1}$
}

\author{
Fernanda Cabral ${ }^{1}$ \\ Carlos Baptista Barcaui ${ }^{1}$ \\ Alexandre Carlos Gripp ${ }^{1}$
}

DOI: http:// dx.doi.org/10.1590/abd1806-4841.20164813

\begin{abstract}
Lichen sclerosus is an uncommon inflammatory dermatosis with preferential involvement of the urogenital region. The extragenital involvement is uncommon and is characterized by small rounded macules or papules, pearly white in color. The coexistence of lichen sclerosus and scleroderma plaques in most cases with extragenital location has been reported in the literature. We report a case of lichen sclerosus associated with scleroderma in children, highlighting the importance of dermoscopy in diagnosis.
\end{abstract}

Keywords: Dermoscopy; Lichen sclerosus et atrophicus; Scleroderma localized

Female patient, 9 years old, white, with asymptomatic hypochromic lesions initially on the hands with subsequent progression to feet and knees, for about 8 months. Dermatological examination revealed polygonal, pearly papules, with parchment-like surface, which agglomerated on plaques in hands, feet and knees (Figure 1). Some of these lesions presented central blackish points. On the right wrist and dorsum of the feet there were poorly defined areas of hyperpigmentation and skin atrophy, intermingled with hypochromic lesions described above (Figure 2). General physical and laboratory examination showed no alterations. Dermoscopy of hand, feet and knees lesions showed multiple whitish areas, some surrounded by an erythematous halo, with the presence of whitish amorphous areas and pseudocomedones (Figure 3). On the clinical and dermoscopic findings the diagnosis of extragenital lichen sclerosus associated with localized scleroderma was established.

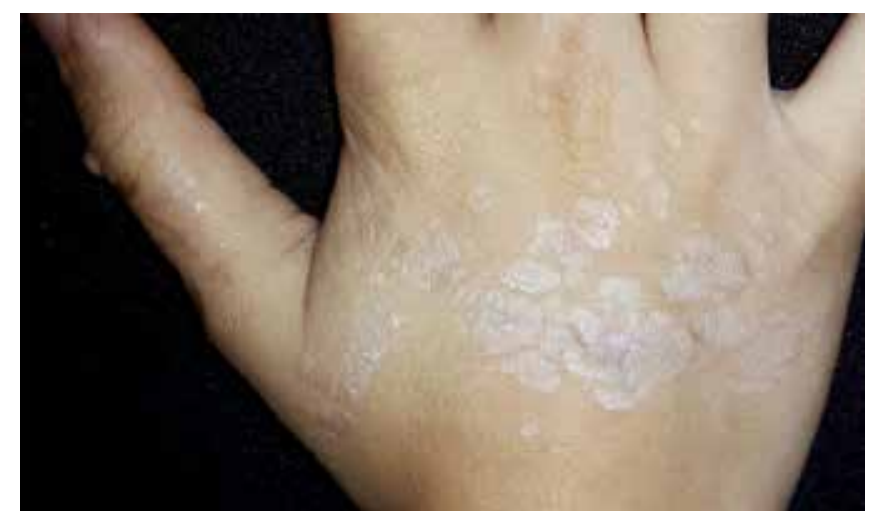

Figure 1: Pearly papules lesions, polygonal, confluent, with parchment-like surface, on the back of the hand

Approved by the Advisory Board and accepted for publication on 02.10.2015

Study performed at Hospital Universitário Pedro Ernesto - Universidade do Estado do Rio de Janeiro (HUPE-UERJ) - Rio de Janeiro (RJ), Brazil. Financial Support: None.

Conflict of Interest: None.

1 Universidade do Estado do Rio de Janeiro (UERJ) - Rio de Janeiro (RJ), Brazil.

(C)2016 by Anais Brasileiros de Dermatologia 


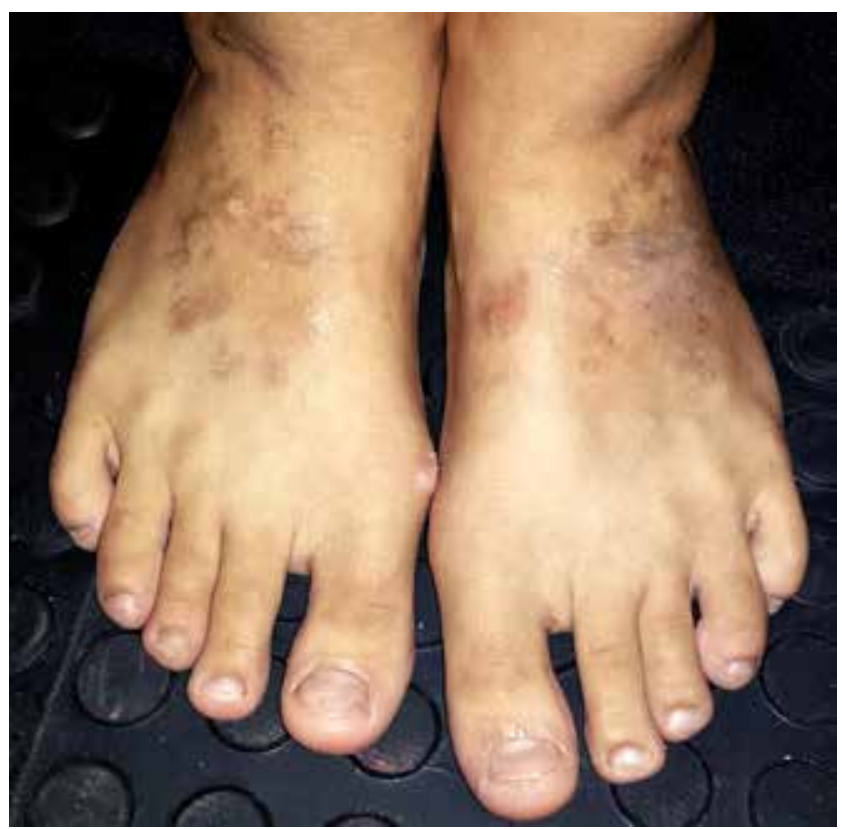

FIGURE 2: White-pearly papules surrounded by hyperchromic halo, poorly delimited, associated with areas of atrophy, on the back of the foot

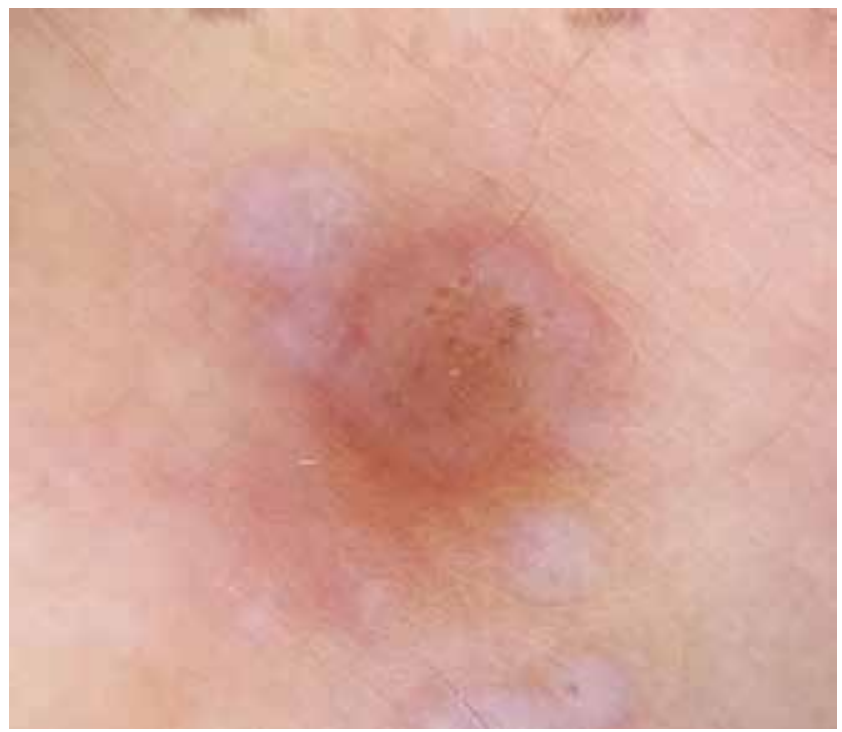

FIGURE 3: Dermoscopy of the lesions on the back of the hand: multiple whitish areas, some surrounded by an erythematous halo, with the presence of whitish amorphous areas and pseudo-comedones

Lichen sclerosus (LS) was first described in the late nineteenth century by Hallopeau. ${ }^{1}$ It is considered a chronic inflammatory dermatosis of the dermal papilla, which is characterized by the presence of asymptomatic white polygonal papules that coalesce to form a plaque with points corresponding to follicular pseudo-aperture. ${ }^{2-4}$ With time these lesions become increasingly atrophic with rough surface. ${ }^{5}$ Classically it occurs in the genital area, but it also has extragenital manifestations, with a variety of clinical presentations. ${ }^{3}$ LS can exist in isolation in $6 \%$ of cases, or in association with

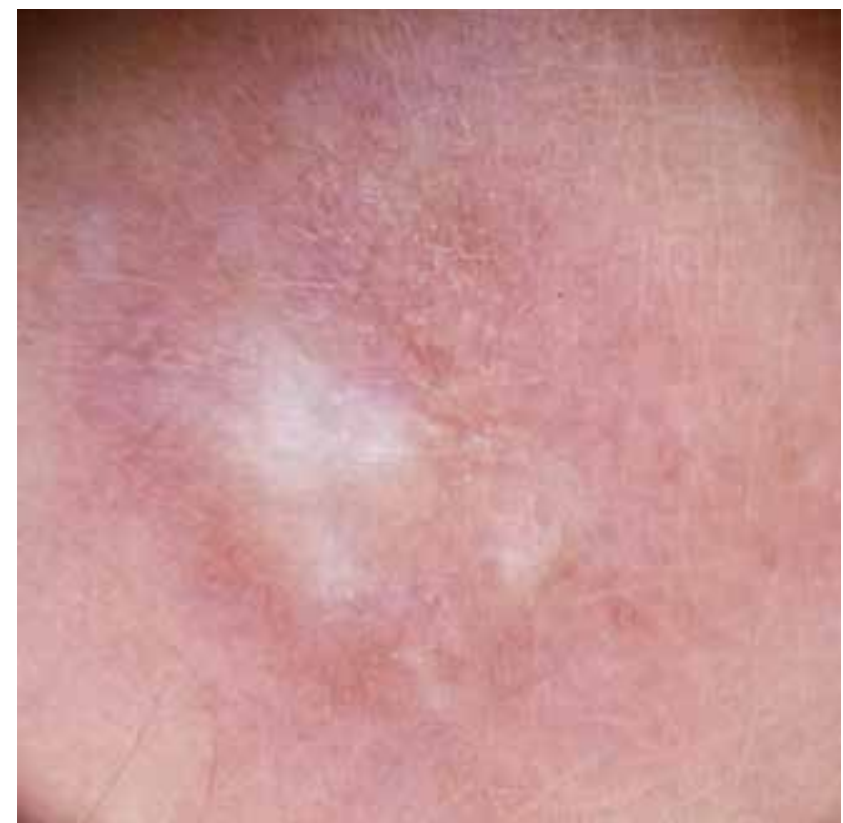

Figure 4: Dermoscopy showing disease activity: amorphous whitish central area and erythematous halo in the lesion on the back of the hand

genital LS in $15-20 \%$ of presentations. ${ }^{3-5}$ The disease affects people of any age but is rare in childhood, with an estimated prevalence of at least 1 in 900 children. When present in children, the appearance of symptoms occurs between two and five years of age. ${ }^{4}$

The etiology is still not clear, but there is evidence of association with HLA Class I antigens and with HLA-A29/B44, infections by human papillomavirus (HPV) and spirochete Borrelia burgdorferi, autoimmune and hormonal phenomena, and trauma (through the Koebner phenomenon). ${ }^{4,6}$ There may be an overlap between LS and morphea, considered as two distinct entities. ${ }^{4} \mathrm{~A}$ recent study with 472 patients indicates that there is a higher frequency of LS in patients with localized scleroderma than in the general population, suggesting a common physiopathological autoimmune mechanism. ${ }^{7}$

Diagnosis is usually clinical and may be supplemented with dermoscopy, with no need for histopathological examination when the lesions are typical. ${ }^{5}$

In dermoscopy recent LS lesions are characterized by homogeneous whitish areas with erythematous halo (Figure 4), with the presence of yellow circles (follicular pseudo-apertures - comedo-like openings), which complies with the histopathologic features of ortohyperkeratosis and follicular plugging. ${ }^{8}$ Older lesions present no halo, with poorly-defined diffuse margins, corresponding in histopathology to epidermal atrophy with flattening of the rete ridges, fibrosis in upper dermis with lichenoid lymphocytic infiltrate and collagen homogenization. ${ }^{2,8}$

Currently there is still no effective treatment for LS, and the majority of patients are initially treated with potent topic corticosteroids. Alternatives are topic calcineurin inhibitors, topic and systemic retinoid, antimalarial drugs and phototherapy. ${ }^{4,5}$

Dermoscopy is a practical optical tool, easy to handle, which, associated with typical clinical features, can assist in the early diagnosis of LS, with no need for invasive examinations.] 


\section{REFERENCES}

1. Coelho WS, Diniz LM, Souza Filho JB. Líquen escleroso e atrófico - relato de dois casos de apresentação atípica. An Bras Dermatol. 2006;81:S297-300.

2. Garrido-Ríos AA, Alvarez-Garrido $\mathrm{H}$, Sanz-Muñoz $\mathrm{C}$, Aragoneses-Fraile $\mathrm{H}$ Manchado-López P, Miranda-Romero A. Dermoscopy of extragenital lichen sclerosus. Arch Dermatol. 2009;145:1468.

3. Sauder MB, Linzon-Smith J, Beecker J. Extragenital bullous lichen sclerosus. J Am Acad Dermatol. 2014;71:981-4.

4. Stavrianeas NG, Katoulis AC, Kanelleas Al, Bozi E, Toumbis-loannou E. Extragenital lichen sclerosus of childhood presenting as erythematous patches. Indian $\mathrm{J}$ Dermatol Venereol Leprol. 2008;74:59-60.

5. Fistarol SK, Itin PH. Diagnosis and treatment of lichen sclerosus: an update. Am J Clin Dermatol. 2013;14:27-47.

6. Rose AE, Boyd KP, Meehan SA, Latkowski JA. Lichen sclerosus et atrophicus. Dermatol Online J. 2013;19:20714.

7. Kreuter A, Wischnewski J, Terras S, Altmeyer P, Stücker M, Gambichler T. Coexistence of lichen sclerosus and morphea: a retrospective analysis of 472 patients with localized scleroderma from a German tertiary referral center. J Am Acad Dermatol. 2012;67:1157-62.

8. Lacarrubba F, Pellacani G, Verzì AE, Pippione M, Micali G. Extragenital lichen sclerosus: clinical, dermoscopic, confocal microscopy and histologic correlations. J Am Acad Dermatol. 2015;72:S50-2.

\author{
MAILING ADDRESS: \\ Fernanda Cabral \\ Boulevard 28 de Setembro, 77 \\ Vila Isabel \\ 20551-030 - Rio de Janeiro - RJ \\ Brazil \\ Email:fernandacabraldermato@gmail.com
}

How to cite this article: Nóbrega MM, Cabral F, Corrêa MC, Barcaui CB, Bressan AL, Gripp AC. Lichen sclerosus associated with localized scleroderma: dermoscopy contribution. An Bras Dermatol. 2016;91(4):534-6. 